\title{
How serious are common childhood fears?
}

Citation for published version (APA):

Muris, P. E. H. M., Merckelbach, H. L. G. J., Maijer, B. N., \& Prins, E. (2000). How serious are common childhood fears? Behaviour Research and Therapy, 38(3), 217-228. https://doi.org/10.1016/S00057967(98)00204-6

Document status and date:

Published: 01/01/2000

DOI:

10.1016/S0005-7967(98)00204-6

Document Version:

Publisher's PDF, also known as Version of record

\section{Please check the document version of this publication:}

- A submitted manuscript is the version of the article upon submission and before peer-review. There can be important differences between the submitted version and the official published version of record.

People interested in the research are advised to contact the author for the final version of the publication, or visit the DOI to the publisher's website.

- The final author version and the galley proof are versions of the publication after peer review.

- The final published version features the final layout of the paper including the volume, issue and page numbers.

Link to publication

\footnotetext{
General rights rights.

- You may freely distribute the URL identifying the publication in the public portal. please follow below link for the End User Agreement:

www.umlib.nl/taverne-license

Take down policy

If you believe that this document breaches copyright please contact us at:

repository@maastrichtuniversity.nl

providing details and we will investigate your claim.
}

Copyright and moral rights for the publications made accessible in the public portal are retained by the authors and/or other copyright owners and it is a condition of accessing publications that users recognise and abide by the legal requirements associated with these

- Users may download and print one copy of any publication from the public portal for the purpose of private study or research.

- You may not further distribute the material or use it for any profit-making activity or commercial gain

If the publication is distributed under the terms of Article $25 \mathrm{fa}$ of the Dutch Copyright Act, indicated by the "Taverne" license above, 


\title{
How serious are common childhood fears?
}

\author{
Peter Muris $^{\mathrm{a}, *}$, Harald Merckelbach $^{\mathrm{a}}$, Birgit Mayer $^{\mathrm{b}}$, Elske Prins ${ }^{\mathrm{b}}$ \\ ${ }^{a}$ Department of Psychology, Maastricht University, P.O. Box 616, 6200 MD Maastricht, Netherlands \\ ${ }^{\mathrm{b}}$ Department of Experimental Abnormal Psychology, Maastricht University, Maastricht, Netherlands
}

Received in revised form 27 August 1998

\begin{abstract}
Objective: the present study examined the clinical status of common childhood fears. Method: fears of the 290 children aged 8 to 13 years were assessed and then their severity was explored by means of a structured diagnostic interview measuring anxiety disorders according to the criteria of the Diagnostic and Statistical Manual of Mental Disorders (DSM). Results: childhood fears reflect significant anxiety disorders in a substantial minority (i.e. 22.8\%) of the children. Conclusions: in most children, childhood fears are part of the normal development. However, in some children, these fears reflect serious anxiety problems which interfere with daily routine. (C) 2000 Elsevier Science Ltd. All rights reserved.
\end{abstract}

Keywords: Children; Fears; Anxiety disorders

\section{Introduction}

Survey research indicates that 'normal' children and adolescents report a surprisingly large number of fears. For example, Ollendick, King, and Frary (1989) found an average number of 14 fears reported by American and Australian youths aged 7 to 17 years. There is also good evidence to suggest that this number is quite similar across different nationalities (e.g. Ollendick, Yang, King, Dong, \& Akande, 1996). While the large number of fears among youths is a well-established fact, it is far from clear how serious these fears are. In the words of Ollendick and King, 1994, p. 635): "Do children really worry about that many fears on a frequent or regular basis? Do they engage in avoidance behaviours to prevent their occurrence? Do the reported fears interfere with their daily functioning?'.

\footnotetext{
* Corresponding author.

0005-7967/00/\$ - see front matter (C) 2000 Elsevier Science Ltd. All rights reserved.

PII: S0005-7967(98)00204-6
} 
Few studies have addressed these questions. In a study of McCathie and Spence (1991), children were asked to complete the Fear Survey Schedule for Children (FSSC; Ollendick, 1983), an 80-item self-report questionnaire that measures children's levels of fear to various stimuli and situations and the Fear Frequency and Avoidance Survey Schedule for Children (FFASSC; see McCathie \& Spence, 1991). The FFASSC intends to measure the frequency with which children experience the 80 FSSC fear items in terms of having fearful thoughts and avoidance behaviour. McCathie and Spence (1991) found a direct link between the most commonly reported fears on the FSSC and the frequency of fearful thoughts and avoidance behaviours on the FFASSC: not only did children report to have FSSC defined fears, but they also indicated that these fears were accompanied by fearful thoughts and avoidance behaviour. A second study by Ollendick and King (1994) investigated the level of interference associated with common childhood fears. Children first completed the FSSC and then were asked to indicate how much these fears prevented them from doing things they would like to do or things they should do. Results showed that the large majority of children (i.e. more than $60 \%$ ) reported that their fears interfered substantially with their daily activities.

Thus, both studies of McCathie and Spence (1991) and Ollendick and King (1994) suggest that childhood fears are seriously distressing to most children. Still, Ollendick and King (1994) rightly remarked that in order to get a clear picture of the clinical significance of childhood fears, their connection to phobias and other anxiety disorders should be examined. The present study investigated this issue. Fears of primary school children were assessed and then their severity was explored by means of a structured diagnostic interview measuring anxiety disorders according to the criteria of the Diagnostic and Statistical Manual of Mental Disorders (DSM; APA, 1987), i.e. the Anxiety Disorders section of the Diagnostic Interview Schedule for Children (DISC; NIMH, 1992).

A subsidiary aim of the current study was to examine the validity of the recently introduced Screen for Child Anxiety Related Emotional Disorders (SCARED; Birmaher et al., 1997; Muris, Merckelbach, Schmidt \& Mayer, 1999). The SCARED claims to be an instrument for screening anxiety disorders symptoms in children. As the present study assessed DSM-defined anxiety disorders in children with the DISC, we could validate SCARED scores against childhood anxiety disorders.

\section{Method}

\subsection{Subjects}

Subjects were 290 children (132 boys and 158 girls) that were recruited from four regular primary schools in Maastricht and Veldhoven, The Netherlands. Mean age of the children was 10.4 years, S.D. $=1.2$, range $8-13$. The schools were selected from various socio-economic areas to enhance the representativeness of the sample.

\subsection{Assessment}

The short FSSC lists the 10 top intense childhood fears (e.g. 'death or dead people', 'being hit by a car or truck', 'bombing attacks', 'burglar breaking into the house'). Children have to indicate 
their level of fear of these items on a 3-point scale: 'none', 'some' or 'a lot'. These are scored 1, 2 and 3 , respectively, and then summed to yield a total fear score ranging from 10 to 30 .

The SCARED is a 66-item self-report questionnaire measuring anxiety disorders symptomatology. The SCARED consists of 9 DSM-IV (APA, 1994) linked subscales: panic disorder symptoms (13 items, e.g. "When frightened, my heart beats fast"), generalized anxiety disorder symptoms (9 items, e.g. "I worry about things working out for me"), social phobia symptoms (4 items, e.g. "I don't like to be with people I don't know"), separation anxiety disorder symptoms (12 items, e.g. "I don't like being away from my family"), obsessivecompulsive disorder symptoms ( 9 items, e.g. "I have thoughts that frighten me"), traumatic stress disorder symptoms (4 items, e.g. "I have frightening dreams about a very aversive experience I once had"), specific phobia, animal type symptoms (3 items, e.g. "I am afraid of an animal that is not really dangerous"), specific phobia, blood-injection-injury type symptoms (7 items, e.g. "I am afraid to go to the dentist"), and specific phobia, environmental-situational type symptoms ( 5 items, e.g. "I am scared to fly in an airplane"). Children have to rate how frequent they have each symptom using a 3-point scale: 'almost never', 'sometimes' or 'often'. These are scored 0,1 and 2, respectively. SCARED total score and subscale scores can be obtained by summing relevant items.

The child version of the DISC (version 2.3) is a highly structured lay-administered interview instrument designed to assess the more common DSM-III-R (APA, 1987) diagnoses of children and adolescents. Previous research has shown that the instrument possesses adequate testretest reliability (Schwab-Stone, Fisher, Piacentini, Shaffer, Davies \& Briggs, 1993), sufficient interrater reliability (Shaffer et al., 1993) and acceptable validity (Piacentini, Shaffer, Fisher, Schwab-Stone, Davies \& Gioia, 1993). The Anxiety Disorders section of the DISC was employed to get a more precise picture of the severity of children's main fears.

\subsection{Procedure}

Previous research of our group (Muris, Merckelbach \& Collaris, 1997; Muris, Merckelbach, Meesters \& Van Lier, 1998) has shown that the common fears reported by children are a function of the method used to gather relevant information (see, for a similar finding in adults, Kirkpatrick, 1984). Therefore, information about fears of children was obtained along two ways. First, children were simply asked "What do you fear most?" (i.e. free option method). Second, children were given the short version of the FSSC and asked to mark the item that they were most afraid of. Children completed the short version of the FSSC and the SCARED in their classrooms. About one week later, children were interviewed with the DISC by a trained research assistant. First, their most intense free option fear was addressed, then their most feared FSSC item was explored. All interviews were carried out by one and the same research assistant. This person was blind to children's scores on the FSSC and the SCARED.

The severity of children's fears was investigated by means of the DISC. Not only specific phobias were considered, but also other relevant anxiety disorders of which experts had indicated that they might accompany that particular fear (see, for details, Muris, Merckelbach, Mayer \& Meesters, 1998). That is to say, for each free option or FSSC fear a limited set of plausible DISC anxiety diagnoses rather than the complete range of anxiety disorders was checked. For instance, for the FSSC item 'death or dead people' the criteria for specific phobia 
Table 1

Examples of fear items with corresponding anxiety disorders

Death/accident self

Getting lost in a strange place

Bombing attacks: being invaded

Spiders

A burglar breaking into our house

Thunderstorms

Fire: getting burned

Falling from high places

Being kidnapped

Germs or getting a serious illness

Not being able to breathe
Generalized anxiety disorder; specific phobia: blood-injection-injury type

Separation anxiety disorder

Generalized anxiety disorder

Specific phobia: animal type

Generalized anxiety disorder

Specific phobia: environmental-situational type

Specific phobia: blood-injection-injury type; traumatic stress disorder

Specific phobia: environmental-situational type

Generalized anxiety disorder; separation anxiety disorder

Obsessive-compulsive disorder;

specific phobia: blood-injection-injury type; generalized anxiety disorder

Specific phobia: blood-injection-injury type; panic disorder

(blood-injection-injury type), separation anxiety disorder and generalized anxiety disorder were assessed. Table 1 shows examples of fear items with corresponding anxiety disorders. Children who fulfilled the full criteria of that anxiety disorder were defined as 'clinical' cases. Children who had the key symptom of a certain anxiety disorder (described in the DSM as the essential feature; APA, 1987, 1994; see Spence, 1997 for a comprehensive overview of the key symptoms of childhood anxiety disorders) but did not meet the full range of diagnostic criteria for that particular disorder were defined as 'subclinical' cases. Alternatively, children who did not have the key symptom were defined as 'nonclinical' cases.

\section{Results}

\subsection{Fear rank orders}

Tables 2 and 3 present the fear rank orders obtained by the free option method and the

Table 2

Fear rank order based on the free option method $(N=290)$

\begin{tabular}{llc}
\hline & No. of subjects & Percentage of sample \\
\hline (1) Spiders & 34 & 11.7 \\
(2) Death/accident others & 28 & 9.7 \\
(3) Death/accident self & 19 & 6.6 \\
(4) Being kidnapped & 19 & 6.6 \\
(5) The dark & 18 & 6.2 \\
(6) Burglar breaking into the house & 17 & 5.9 \\
(7) Home alone in the evening & 15 & 5.2 \\
(8) Thunderstorms & 12 & 4.1 \\
(9) Snakes & 10 & 3.4 \\
(10) Frightening movies & 10 & 3.4 \\
\hline
\end{tabular}


Table 3

FSSC based fear rank order

\begin{tabular}{llll}
\hline FSSC -item & $\begin{array}{l}\text { No. of subjects who } \\
\text { endorsed this item }\end{array}$ & $\begin{array}{l}\text { Percentage } \\
\text { of sample }\end{array}$ & $\begin{array}{l}\text { Percentage of subjects } \\
\text { rating 3 ('a lot') }\end{array}$ \\
\hline (1) Not being able to breathe & 53 & 18.3 & 64.8 \\
(2) Burglar breaking into our house & 43 & 14.8 & 26.6 \\
(3) Bombing attacks/being invaded & 30 & 10.3 & 58.6 \\
(4) Falling from a high place & 30 & 10.3 & 50.7 \\
(5) Death/dead people & 29 & 10.0 & 10.0 \\
(6) Getting lost in a strange place & 28 & 9.7 & 19.7 \\
(7) Being hit by a car or truck & 25 & 8.6 & 55.9 \\
(8) Getting a serious illness & 22 & 7.6 & 43.1 \\
(9) Fire/getting burned & 18 & 6.2 & 33.1 \\
(10) Spiders & 12 & 4.1 & 11.4 \\
\hline
\end{tabular}

${ }^{\mathrm{a}} \mathrm{FSSC}=$ Fear Survey Schedule for Children.

${ }^{\mathrm{b}}$ Number of subjects who endorsed this item of the short version of the FSSC as their top intense fear.

short version FSSC. It is worthy of note that the fear rank order obtained by the free option method was highly similar to that found in other studies employing this method (Muris et al., 1997, 1998). "Not being able to breathe" was the top intense FSSC fear item, while 'spiders' was the most prevalent item in the free option ranking.

\subsection{Anxiety symptoms related to children's main fears}

Table 4 shows percentages of children who exhibited DISC anxiety disorder symptoms in relation to their main fears. As can be seen in the left columns of Table $4,49.0 \%$ of the children had symptoms of at least 1 anxiety disorder at a subclinical level. Note also that subclinical symptoms of specific phobia (percentages between 11.7 and 13.4\%), generalized anxiety disorder $(14.5 \%)$ and separation anxiety disorder $(14.8 \%)$ were most common.

When applying more stringent criteria (i.e. clinical cases), these percentages were considerably lower (see right columns of Table 4). Nevertheless, $22.8 \%$ of the children fulfilled the criteria for at least 1 DSM-III-R anxiety disorder. Again, specific phobias (percentages between 4.5 and $7.9 \%$ ), generalized anxiety disorder $(5.5 \%)$ and separation anxiety disorder $(4.8 \%)$ were most prevalent.

Table 5 presents the percentages of children who fulfilled the DISC criteria for 0,1 or multiple anxiety disorders. As can be seen, most children had either no or only 1 anxiety disorder. Nevertheless, percentages of children who reported to have multiple anxiety disorders were $16.9 \%$ for the subclinical cases and $7.2 \%$ for the clinical cases.

Finally, it should be mentioned that fears obtained with the free option method were more frequently connected to subclinical and clinical anxiety disorder symptoms than were FSSC 
Table 4

Percentages of children who exhibited DISC anxiety symptoms in relation to their main fears $(N=290$; DISC $=$ Diagnostic Interview Schedule for Children; FSSC = Fear Survey Schedule for Children)

\begin{tabular}{|c|c|c|c|c|c|c|}
\hline & \multicolumn{3}{|l|}{ Subclinical } & \multicolumn{3}{|l|}{ Clinical } \\
\hline & Free option method ${ }^{\mathrm{a}}$ & FSSC method ${ }^{\mathrm{b}}$ & Both methods ${ }^{\mathrm{c}}$ & Free option method ${ }^{\mathrm{a}}$ & FSSC method ${ }^{\mathrm{b}}$ & Both methods ${ }^{\mathrm{c}}$ \\
\hline \multicolumn{7}{|l|}{ DISC symptoms of: } \\
\hline $\begin{array}{l}\text { Specific phobia: situational- } \\
\text { environmental }\end{array}$ & 9.0 & 4.5 & 11.7 & 3.4 & 1.0 & 4.5 \\
\hline $\begin{array}{l}\text { Specific phobia: blood-- } \\
\text { injection-injury }\end{array}$ & 3.8 & 10.7 & 12.8 & 2.4 & 6.6 & 7.9 \\
\hline Specific phobia: animal & 13.1 & 3.8 & 13.4 & 6.9 & 2.4 & 7.2 \\
\hline Social phobia & 1.0 & 0.0 & 1.0 & 0.3 & 0.0 & 0.3 \\
\hline $\begin{array}{l}\text { Generalized anxiety } \\
\text { disorder }\end{array}$ & 14.1 & 13.8 & 14.5 & 5.5 & 5.5 & 5.5 \\
\hline Separation anxiety disorder & 13.8 & 6.2 & 14.8 & 4.8 & 1.7 & 4.8 \\
\hline $\begin{array}{l}\text { Obsessive-compulsive } \\
\text { disorder }\end{array}$ & 0.3 & 0.0 & 0.3 & 0.0 & 0.0 & 0.0 \\
\hline Panic disorder & 1.4 & 1.0 & 1.7 & 1.4 & 1.0 & 1.7 \\
\hline $\begin{array}{l}\text { Symptoms of at least } 1 \\
\text { anxiety disorder }\end{array}$ & 45.2 & 32.8 & 49.0 & 20.3 & 14.3 & 22.8 \\
\hline
\end{tabular}

${ }^{a}$ DISC anxiety symptoms in relation to the fear that was identified by means of the free option method.

${ }^{\mathrm{b}}$ DISC anxiety symptoms in relation to the most feared FSSC item.

${ }^{c}$ DISC anxiety symptoms in relation to both free option and FSSC fears. 
Table 5

Percentages of children with $0,1,2,3$ or 4 (subclinical) DISC anxiety disorders $(N=290 ;$ DISC $=$ Diagnostic Interview Schedule for Children)

\begin{tabular}{lcc}
\hline & Subclinical & Clinical \\
\hline No anxiety disorder & 51.0 & 77.2 \\
1 anxiety disorder & 32.1 & 15.5 \\
2 anxiety disorders & 13.1 & 5.5 \\
3 anxiety disorders & 3.1 & 1.4 \\
4 anxiety disorders & 0.7 & 0.3 \\
\hline
\end{tabular}

fears. The only exception to this rule were blood-injection-injury phobia symptoms which were more often found in relation to FSSC fears (see Table 4).

\subsection{Relationship between SCARED and DISC anxiety symptoms}

Due to the relatively small sample size, the relationship between SCARED and DISC was only explored for the five most prevalent subclinical anxiety disorder symptoms, i.e. the three types of specific phobia, generalized anxiety disorder and separation anxiety disorder. First,

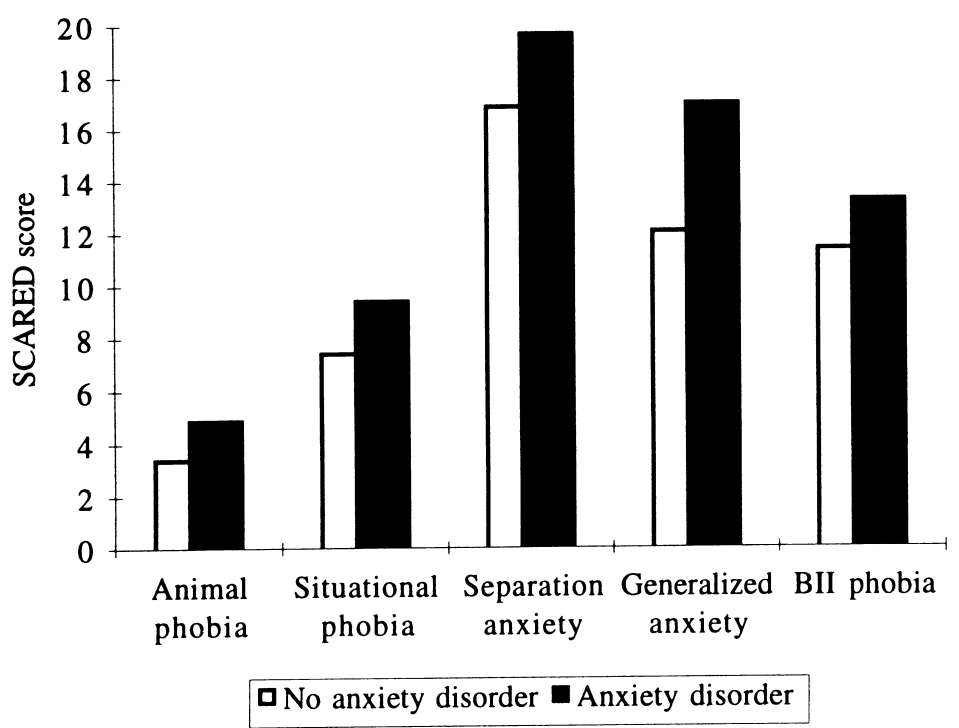

Fig. 1. SCARED subscale scores of children with subclinical anxiety disorder symptoms and children without such symptoms. Note. SCARED= Screen for Child Anxiety Related Emotional Disorders; BII phobia=blood-injectioninjury phobia. 
Table 6

Results of the discriminant analyses: optimal cutoff scores, sensitivity, and specificity values for the separate SCARED scales

\begin{tabular}{lllll}
\hline & Range & Optimal cutoff & Sensitivity (\%) & Specificity (\%) \\
\hline SCARED & & & & 67.6 \\
Total anxiety symptoms score & & 33 & 70.3 & 51.2 \\
Specific phobia: situational-environmental & $0-10$ & 3 & 62.2 & 58.5 \\
Specific phobia: blood-injection-injury & $0-14$ & 5 & 76.9 & 56.9 \\
Specific phobia: animal & $0-6$ & 2 & 72.1 & 56.3 \\
Generalized anxiety disorder & $0-24$ & 8 & 75.4 & 71.4 \\
Separation anxiety disorder & $0-18$ & 5 & & \\
\hline
\end{tabular}

\footnotetext{
${ }^{\text {a }}$ SCARED $=$ Screen for Child Anxiety Related Emotional Disorders; discriminant analyses were only carried out for the SCARED scales of those anxiety disorders for which a sufficient number of children reported (subclinical) symptoms on the DISC.

${ }^{\mathrm{b}}$ Optimal cutoff between children who had at least 1 (subclinical) anxiety disorder and children who had no subclinical anxiety disorder.
}

analyses of variance with sex and age as covariates (ANCOVAs) were carried out in order to investigate whether children with subclinical symptoms of a particular anxiety disorder score significantly higher on the corresponding SCARED subscale than children without such symptoms. The ANCOVAs revealed that this was the case for all five comparisons (see Fig. 1). $F(1,286)$ values were $13.5(P<0.001)$ for animal phobia, $12.6(P<0.001)$ for environmentalsituational phobia, $15.8(P<0.001)$ for separation anxiety disorder, $65.9(P<0.001)$ for generalized anxiety disorder and $6.6(P<0.05)$ for blood-injection-injury phobia.

Discriminant analyses were carried out to determine cutoff scores of the SCARED that optimally distinguished between children with subclinical anxiety disorder symptoms and children without such symptoms. Table 6 summarizes the results of these analyses. Not only optimal SCARED cutoff scores are shown, but also their corresponding sensitivity (i.e. the probability that a person with the condition will be classified by means of the SCARED as having the condition) and specificity (i.e. the probability that a person without the condition will be classified as being without the condition).

\section{Discussion}

Numerous studies have shown that childhood fears are common (see, for a review, Ollendick, Hagopian \& King, 1997). In order to get a more precise picture of the clinical significance of these fears, the present study investigated whether childhood fears are related to clinical phobias and other anxiety disorders. Results showed that fears were associated with subclinical manifestations of anxiety disorders in $49.0 \%$ of the children. Moreover, about one fifth of the children $(22.8 \%)$ appeared to meet the full criteria of an anxiety disorder. Taken 
together, the present findings strongly suggest that a considerable number of the childhood fears qualify for a (subclinical) anxiety disorder.

In line with earlier studies on the prevalence of anxiety disorders, the present investigation found specific phobias, generalized anxiety disorder and separation anxiety disorder to be the most prevalent anxiety disorders (e.g. Bell-Dolan, Last \& Strauss, 1990; Costello et al., 1996). Remarkably, the prevalence rate of anxiety disorders in the current study $(22.8 \%)$ was somewhat higher than that found in most other community surveys on anxiety disorders in children (i.e. between 5.7 and 17.7\%; see, for a review, Costello \& Angold, 1995). With regard to the high prevalence rate of anxiety disorders in the present study, two remarks are in order. The first has to do with the procedure followed in the current study. That is, children were interviewed twice with (some sections of) the DISC (the first time in relation to the fear that was identified by means of the free option method, the second time in relation to the most feared FSSC item) and this may have elicited overreporting of anxiety symptoms by the children. On the other hand, it should be noted that in the present study, for each fear only a limited set of plausible DISC anxiety diagnoses rather than the complete range of anxiety disorders was checked. It is possible that some of the fear items were connected to a less obvious anxiety disorder and that in these cases a diagnosis was missed, resulting in underreporting of anxiety symptoms. Second, the present data pertain to children aged 8 to 13 years. It cannot be ruled out that other prevalence rates are found in more heterogenous age samples.

The present data indicate that, in a substantial minority of the children, childhood fears reflect serious anxiety problems which interfere with children's daily routine (see, for a similar conclusion, Ialongo, Edelsohn, Wertkamer-Larsson, Crockett \& Kellam, 1995). The question remains how serious these problems are in the long run. Obviously, prospective, longitudinal studies are needed to determine the extent to which childhood anxiety disorders are persistent. Such studies are beginning to emerge. For example, Last, Perrin, Hersen and Kazdin (1996) followed a group of clinically referred children with anxiety disorders for 3 to 4 years. Results showed that a high remission rate with more $80 \%$ of the children no longer fulfilling the diagnostic criteria for their initial anxiety disorder. Interestingly, early age of onset and older age at intake were factors predicting slower recovery. In a epidemiological sample of 9 to 18year-old children, Cohen, Cohen and Brook (1993) prospectively investigated the persistence of childhood psychiatric disorders. Results indicated that overanxious disorder which was the only anxiety disorder that was examined in this study, was relatively stable. That is, $47 \%$ of the cases were rediagnosed at $2 \frac{1}{2}$ year follow-up. Altogether, available evidence suggests that although anxiety disorders in many children remit, there is also a considerable proportion of the youths with continuing anxiety problems.

An obvious limitation of the present study is that it solely relied on children's self-report of anxiety disorders. Additional DISC interviews of the parents would have yielded more precise information about the connection between childhood fears and anxiety disorders.

As for the connection between specific childhood fears and anxiety disorders, two remarks are in order. To begin with, the current data suggest that the relationship between dominant childhood fears and anxiety disorders is not very specific. For example, 'spiders' is clearly associated with specific phobia. Yet, 'germs or getting a serious illness' may be connected to blood-injection-injury phobia, generalized anxiety disorder or even obsessive-compulsive 
disorder (see, for a similar conclusion, Last, Francis \& Strauss, 1989; Muris et al., 1998). A second point is that free option fears were more often associated with anxiety disorder symptoms than FSSC fears. Given the fact that the short version of the FSSC only lists 10 fear items, this result is hardly surprising. The free option method yields a large number of fears, thereby enhancing the possibility to detect a related anxiety disorder.

An additional purpose of the present study was concerned with the validity of the SCARED. Results showed that children with subclinical symptoms of an anxiety disorder scored significantly higher on the corresponding SCARED subscale than children without such symptoms. Furthermore, discriminant analyses yielded highly similar findings to those obtained in a previous study of Birmaher et al. (1997) who examined clinically referred children. That is, the sensitivity of the SCARED subscales was about $70 \%$, whereas the specificity appeared to be $50 \%$ or higher. Unfortunately, due to the relatively small sample size, the discriminant analyses could only be carried out for 5 of the 9 SCARED subscales. Clearly, the validity of the other SCARED subscales warrants further research. But as things stand, the SCARED seems to be a promising instrument for screening anxiety disorders in children.

\subsection{Clinical implications}

In conclusion, then, the current investigation demonstrates that childhood fears are not only frequent, but also reflect significant anxiety disorders in a substantial minority of the 8 to 13year-old children. In the light of these findings, there seems to be a need for early intervention programs for childhood anxiety problems. Dadds, Spence, Holland, Barrett and Laurens (1997) have already tested such a program. In their study, 128 anxiety disordered children were assigned to either a 10-week school-based cognitive-behavioral intervention or to a nointervention control group. Both groups were found to improve from pre- to post assessment. However, at 6 months follow-up, the improvement only maintained in the intervention group. That is, in this group, the rate of existing anxiety disorders was reduced, and the onset of new anxiety disorders was prevented. These results indicate that anxiety problems and disorders in children can be successfully treated through an early intervention school-based program.

\section{Acknowledgements}

The teachers and staff of primary schools 'Anne Frank', 'Joppenhof' and 'De Poort' in Maastricht and 'Op Dreef' in Veldhoven, The Netherlands are acknowledged for their participation in the present study.

\section{References}

APA (1987). Diagnostic and statistical manual of mental disorders (3rd ed., revised (DSM-III-R)). Washington, DC: American Psychiatric Association. 
APA (1994). Diagnostic and statistical manual of mental disorders (4th ed. (DSM-IV)). Washington, DC: American Psychiatric Association.

Bell-Dolan, D. J., Last, C. G., \& Strauss, C. D. (1990). Symptoms of anxiety disorders in normal children. J. Am. Acad. Child Adolesc. Psychiatry, 29, 759-765.

Birmaher, B., Khetarpal, S., Brent, D., Cully, M., Balach, L., Kaufman, J., \& McKenzie Neer, S. (1997). The Screen for Child Anxiety Related Emotional Disorders (SCARED): scale construction and psychometric characteristics. J. Am. Acad. Child Adolesc. Psychiatry, 36, 545-553.

Cohen, P., Cohen, J., \& Brook, J. (1993). An epidemiological study of disorders in late childhood and adolescence. II. Persistence of disorders. J. Child Psychol. Psychiatry, 34, 869-877.

Costello, E. J., \& Angold, A. (1995). Epidemiology. In J. S. March, Anxiety disorders in children and adolescents. New York: Guilford Press.

Costello, E. J., Angold, A., Burns, B. J., Stangl, D. K., Tweed, D. L., Erkanli, A., \& Worthman, C. M. (1996). The Great Smoky Mountains study of youth. Arch. Gen. Psychiatry, 53, 1129-1136.

Dadds, M. R., Spence, S. H., Holland, D. E., Barrett, P. M., \& Laurens, K. R. (1997). Prevention and early intervention for anxiety disorders: a controlled trial. J. Consult. Clin. Psychol., 65, 627-635.

Ialongo, N., Edelsohn, G., Werthamer-Larsson, L., Crockett, L., \& Kellam, S. (1995). The significance of selfreported anxious symptoms in first grade children: prediction to anxious symtoms and adaptive functioning in fifth grade. J. Child Psychol. Psychiatry, 36, 427-437.

Kirkpatrick, D. R. (1984). Age, gender, and patterns of common intense fears among adults. Behav. Res. Ther., 19, 109-115.

Last, C. G., Francis, G., \& Strauss, C. C. (1989). Assessing fears in anxiety-disordered children with the revised Fear Survey Schedule for Children. J. Clin. Child Psychol., 18, 137-141.

Last, C. G., Perrin, S., Hersen, M., \& Kazdin, A. E. (1996). A prospective study of childhood anxiety disorders. J. Am. Acad. Child Adolesc. Psychiatry, 35, 1502-1510.

McCathie, H., \& Spence, S. H. (1991). What is the revised Fear Survey Schedule for Children measuring? Behav. Res. Ther., 29, 495-502.

Muris, P., Merckelbach, H., \& Collaris, R. (1997). Common childhood fears and their origins. Behav. Res. Ther., 35, 929-937.

Muris, P., Merckelbach, H., Mayer, B., \& Meesters, C. (1998). Common fears and their relationship to anxiety disorders symptomatology in normal children. Person Individ. Diff., 24, 575-578.

Muris, P., Merckelbach, H., Meesters, C., \& Van Lier, P. (1998). What do children fear most? J. Behav. Ther. Exp. Psychiatry, 28, 263-267.

Muris, P., Merckelbach, H., Schmidt, H., \& Mayer, B. (1999). The revised version of the Screen for Child Anxiety Related Emotional Disorders (SCARED-R): factor structure in normal children. Person Individ. Diff., 26, $99-112$.

NIMH (National Institute of Mental Health) (1992). Diagnostic Interview Schedule for Children (DISC) (Version 2.3.). New York: New York State Psychiatric Institute, Division of Child and Adolescent Psychiatry.

Ollendick, T. H. (1983). Reliability and validity of the revised Fear Survey Schedule for Children (FSSC-R). Behav. Res. Ther., 21, 685-692.

Ollendick, T. H., Hagopian, L. P., \& King, N. J. (1997). Specific phobias in children. In G. C. L. Davey, Phobias. A handbook of theory, research and treatment. Chichester: Wiley.

Ollendick, T. H., \& King, N. J. (1994). Fears and their level of interference in adolescents. Behav. Res. Ther., 32, 635-638.

Ollendick, T. H., King, N. J., \& Frary, R. B. (1989). Fears in children and adolescents: reliability and generalizability across gender, age, nationality. Behav. Res. Ther., 27, 19-26.

Ollendick, T. H., Yang, B., King, N. J., Dong, Q., \& Akande, A. (1996). Fears in American, Australian, Chinese and Nigerian children and adolescents: a cross-cultural study. J. Child Psychol. Psychiatry, 37, 213-220.

Piacentini, J., Shaffer, D., Fisher, P., Schwab-Stone, M., Davies, M., \& Gioia, P. (1993). The Diagnostic Interview Schedule for Children-revised version (DISC-R). III. Concurrent criterion validity. J. Am. Acad. Child Adolesc. Psychiatry, 32, 658-665.

Schwab-Stone, M., Fisher, P., Piacentini, J., Shaffer, D., Davies, M., \& Briggs, M. (1993). The Diagnostic Interview Schedule for Children-revised version (DISC-R). II. Test-retest reliability. J. Am. Acad. Child Adolesc. Psychiatry, 32, 651-657. 
Shaffer, D., Schwab-Stone, M., Fisher, P., Cohen, P., Piacentini, J., Davies, M., Conners, K., \& Regier, D. (1993). The Diagnostic Interview Schedule for Children-revised version (DISC-R). I. Preparation, field testing, interrater reliability, and acceptability. J. Am. Acad. Child Adolesc. Psychiatry, 32, 643-650.

Spence, S. H. (1997). Structure of anxiety symptoms among children: a confirmatory factor-analytic study. J. Abn. Psychol., 106, 280-297. 